\title{
DE POËZIE IN HET BATAKSCHE VOLKSLEVEN.
}

\author{
DOOR
}

\section{A. VAN OPHUIJSEN.}

Rien n'est peu de chose.

\author{
V. Hugo.
}

Gedurende mijn zevenjarig verblijf in de Bataklanden (Mandaïling en Angkola) maakte ik steeds zooveel mogelijk aanteekeningen omtrent hetgeen ik zag en hoorde. Zoo kwam ik langzamerhand in het bezit van eene groote menigte spreekwoorden, spreekwijzen, raadsels, liedjes, enz. Mijn plan was ze te ordenen en te schiften en aan eenig genootschap ter uitgave aan te bieden. De brand echter, die den 13den Januari 1885 een groot gedeelte van Padang Sidimpoewan in de asch legde, vernietigde ook mijne uitgebreide verzameling handschriften en aanteekeningen.

Daar het natuurlijk onmogelijk is, alles wat ik vroeger verzamelde, weer bijeen te brengen - de tijd en vooral de gelegenheid daartoe ontbreken - acht ik het wenschelijk, zoo spoedig als de omstandigheden het mij toelaten, zooveel bekend te maken, als ik mij nog herinner van 't geen ik vóór den brand op schrift had.

De bijdragen, die ik mij voorstel achtereenvolgens het licht te doen zien, hadden belangrijker kunnen zijn. Maar 't woord van Victor Hugo, dat ik tot motto koos; deed mij besluiten niet langer te wachten, maar te geven, wat ik nog geven kan.

In dit eerste opstel wensch ik het een en ander mede te deelen omtrent de "bloementaal" der Bataks.

Ik zeg "bloementaal", beter zou 't zijn van "bladerentaal" te spreken. Want blaren en niet bloemen, zooals de Westerlingen, gebruiken de Bataksche jongelingen en jonge meisjes om elkander 
mede te deelen, wat hun op het hart ligt. De bladeren op zich zelf hebben geene beteekenis; hun naam echter geeft min of meer gewijzigd 't bedoelde woord aan, rijmt om zoo te zeggen daarop.

B. v. bladeren van de gewone pau (mal. paku, een varensoort) beteekenen $a$ (ik); die van de pau rara (roode varen) $=r a$ (willen) of wel ra au (ik wil).

Niet alleen bladeren echter doen dienst als tolken tusschen geliefden, al zijn zij ook de voornaamste en dikwijls eenige deelen van eenen minnebrief. Kralen, belletjes, mieren komen er ook bij te pas, ja zelfs afbeeldingen van voorwerpen, als een prauw, de steel van een bijl, enz.

Of bij andere volken ook voorbeelden gevonden worden van een bladerentaal is mij niet bekend; dat afbeeldingen van voorwerpen dienen om gebeurtenissen te vermelden of mededeelingen te doen, daarvan zien wij vele bewijzen vermeld in het vijfde hoofdstuk van Tylor's Early history of mankind, getiteld : picture-writing and wordwriting.

Hetzelfde onderscheid echter, dat wij vinden tusschen de bloementaal der Europeanen, waarin iedere bloem, afgescheiden van haren naam, eene eigene beteekenis heeft en de Bataksche blarentaal, waarin de naam van het blad als het ware rijmt op het daarmee bedoelde woord, merken we ook weer hier op.

De afbeelding van den steel eener bijl (porda) beteekent bij de Bataks niets anders dan roha (gemoed, enz.), terwijl op een grafsteen van een Indiaansch hoofd in genoemd werk van Tylor afgebeeld, een stuk van een bijl beduiden moet: moed of macht. Een mier (porkis) beteekent niet ijverig of iets van dien aard, maar torkis (gezond).

Toch vinden we voorbeelden, al komen ze ook zeldzaam voor, dat met de afbeelding van 't een of ander voorwerp, dat voorwerp zelf bedoeld wordt of eene handeling, die men daarmede verricht. (Zie hieronder: parau, sige pag. 408.)

Eene lijst van de voor bovengenoemd doel meest gebruikte bladeren en voorwerpen - een Bataksche briefsteller voor minnende harten - geef ik hierbij. 


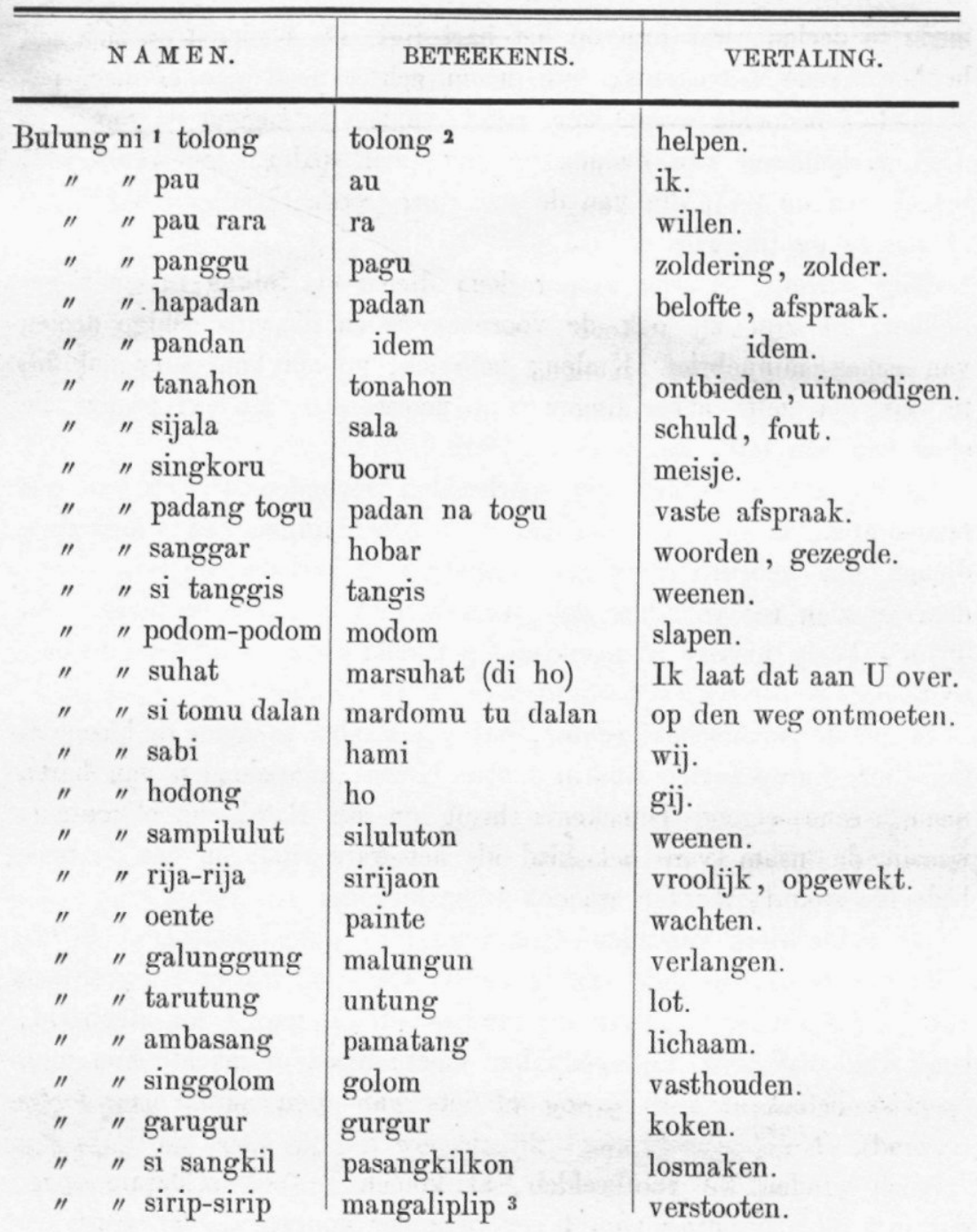

1 Bulung ni = bladeren van; 2 helpen is eigenlijk in 't Bataksch mangurupi

3 mangaliplip (ook mambondarkon) $=$ iemand verstooten, alle gemeenschap met hem afbreken. De verstooter geeft een feestje en deelt daarop mede, dat hij Si anu verstooten heeft (madung kuliplip, kubondarkon, si Anu); de verstootene verlaat gewooulijk zijne kampong. Verg. den naam der kampong: Bunga Bondar (bij Sipirok). - Gotap kotáng beteekent ook: geen gemeenschap met elkander meer hebben, elkander niet meer kennen, elkander geheel vreemd zijn. Gotap kotang ma hita, zeggen twee lui tot elkander en ze zijn voor altijd gescheiden, al blijven ze ook in dezelfde kampong wonen. Als een stuk rotan doorgesneden wordt, passen de snijvlakken niet meer op elkander; deze eigenschap verklaart de uitdrukking gotap kotang. 


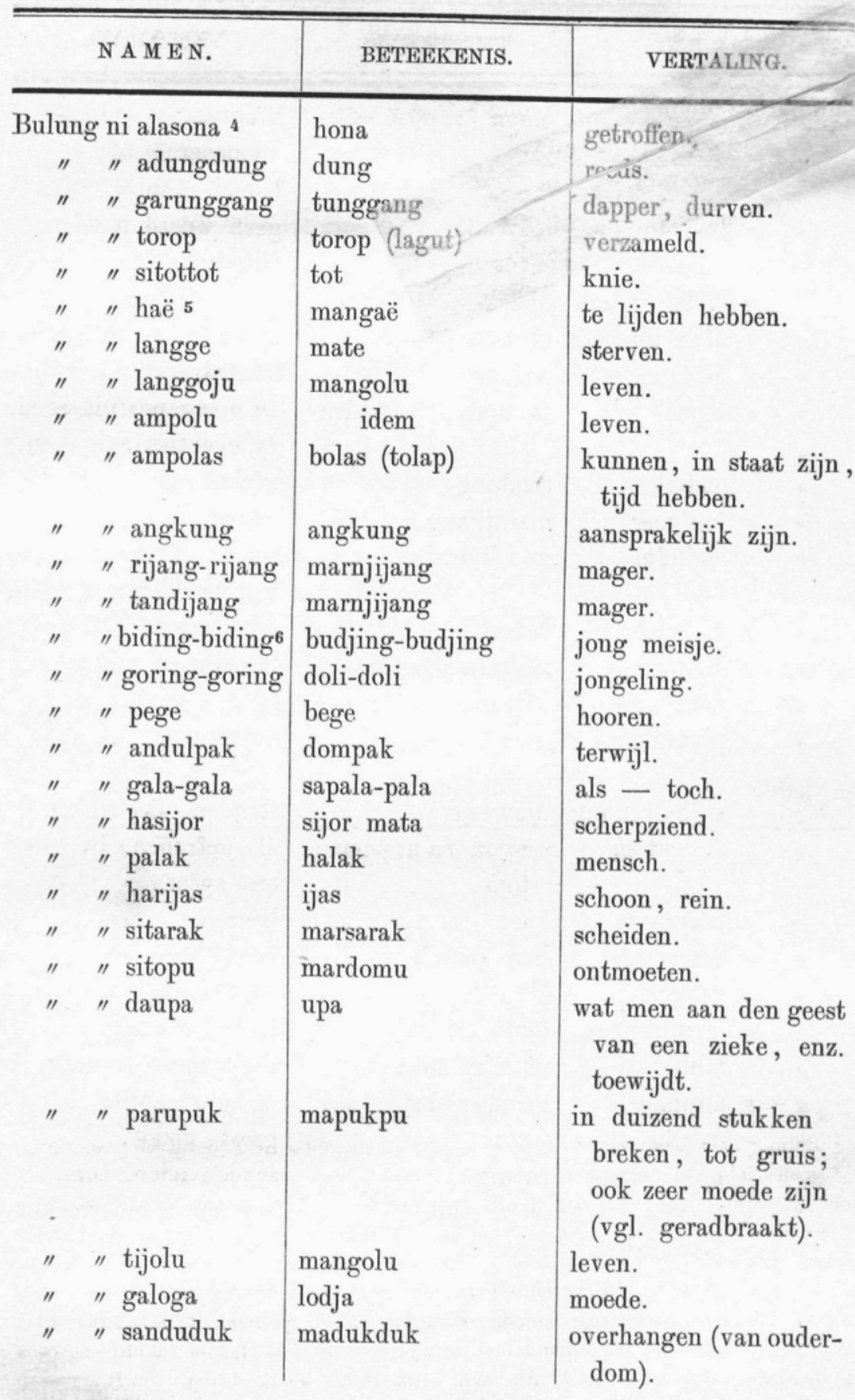

\footnotetext{
4 Te Sipirok: hasona. ${ }^{5}$ Angk, bulu poring. ${ }^{6}$ Angk, buning-buning.
} 


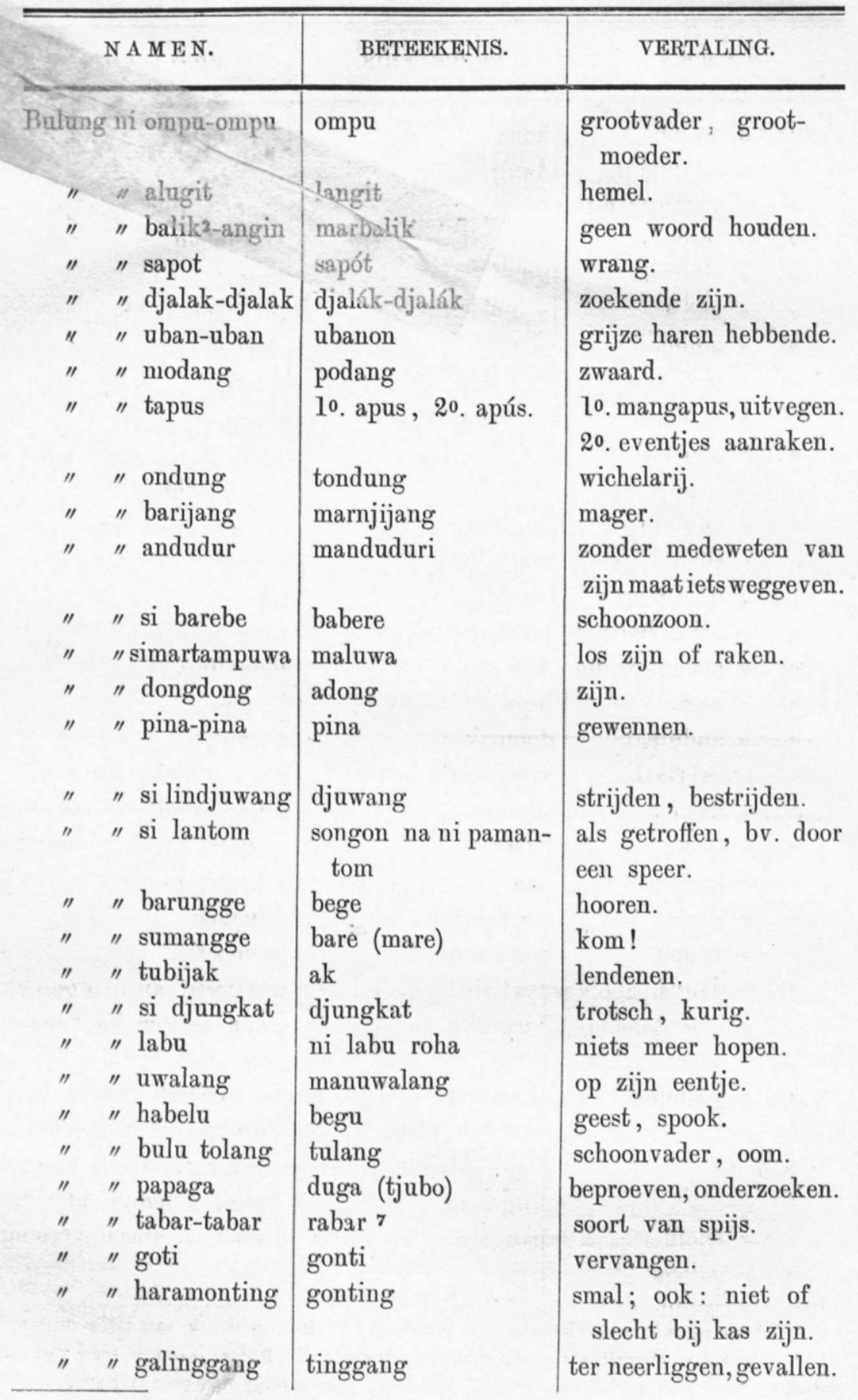

7 = Mal. rudjaq. 


\begin{tabular}{|c|c|c|}
\hline NA MEN. & BETEEKENIS. & VERTALING. \\
\hline $\begin{array}{l}\text { Bulung ni haramambu } \\
\text { " } \quad \text { sirungkas } \\
\text { " " unte tonggi } \\
\text { " " dali } \\
\text { " " tahul-tahul } \\
\text { " " lidi } \\
\text { " " arirang } \\
\text { " " rindang } \\
\text { habong ni subang }{ }^{8} \\
\text { simata *) } \\
\text { giring-giring } \\
\text { porda } \\
\text { borong-borong } \\
\text { porkis }\end{array}$ & $\begin{array}{l}\text { dabu (roha) } \\
\text { rungkás } \\
\text { tondi } \\
\text { mandali } \\
\text { haul } \\
\text { tondi } \\
\text { sirang } \\
\text { gindjang } \\
\text { lubang } \\
\text { mata } \\
\text { miling-iling } \\
\text { roha } \\
\text { morong-orong } \\
\text { torkis }\end{array}$ & $\begin{array}{l}\text { tevreden, voldaan. } \\
\text { flapuit. } \\
\text { geest, ziel. } \\
\text { uitstel vragen. } \\
\text { gelofte. } \\
\text { geest, ziel. } \\
\text { scheiden. } \\
\text { hoog. } \\
\text { gat, opening. } \\
\text { oog. } \\
\text { besluiteloos zijn. } \\
\text { geest. } \\
\text { kreunen. } \\
\text { gezond. }\end{array}$ \\
\hline
\end{tabular}

Eenige voorbeelden van Bataksche minnebrieven mogen tot illustratie dienen van het hierboven medegedeelde.

\begin{tabular}{|c|c|c|}
\hline I N H O U D. & BETEEKENIS. & VERTALING. \\
\hline $\begin{array}{l}\text { 1. Hepeng sagodang } 9 \\
\text { Bulung ni pandan }\end{array}$ & $\begin{array}{l}\text { Taringot tu padan- } \\
\text { tai, godang situtu do } \\
\text { robangku }\end{array}$ & $\begin{array}{l}\text { Ik ben ten zeerste } \\
\text { verheugd over onze af- } \\
\text { spraak. }\end{array}$ \\
\hline $\begin{array}{l}\text { 2. Bulung ni sipabolkas } \\
\text { " " tanaon }\end{array}$ & $\begin{array}{l}\text { Pabolkas djolo to- } \\
\text { nangku tu si..... }\end{array}$ & $\begin{array}{l}\text { Breng mijne woorden } \\
\text { s. v. p. aan haar over. }\end{array}$ \\
\hline $\begin{array}{l}\text { 3. Bulung ni uban-uban } \\
\text { " " galunggung } \\
\text { hodong }\end{array}$ & $\begin{array}{l}\text { Djaru djabat pe } \\
\text { bontar uban kudju- } \\
\text { djung laing ko do lu- } \\
\text { ngunku }\end{array}$ & $\begin{array}{l}\text { Al moet het zoo lang } \\
\text { duren tot mijne haren } \\
\text { grijs geworden zijn, u } \\
\text { alleen bemin ik (eig. } \\
\text { naar u alleen verlang } \\
\text { ik). }\end{array}$ \\
\hline
\end{tabular}




\section{$\overline{\underline{ }}$ \\ I N H O U D. \\ 4. Bul. ni si tarak \\ " " adungdung \\ " " sitata \\ " " sitanggis \\ " " podom-podom \\ " " pau \\ 5. Gambaran ni sige 10 gambaran ni parau rimbang hodong}

6. Hodong Bulung ni pau Mare-mare sontang pining

7. Bulung ni sitopu " sitomu dalan eme (of : bulung ni eme)

8. Bulung ni dapdap " " pau " " hasijor " " salak

Simata

9. Bulung ni pandan " " tuba gambaran ni porda

10. Tali na pudun maté Bulung ni hapadan

10 Mal. sigai.
BETEEKENIS.

VERTALING.

$\mathrm{Na}$ onze scheiding val ik niet in slaap dan na eerst geweend te hebben.

Djaru tu gindjang ko husigei; djaru tu laut kurajari; angkon ko do di au.

Intap ko da angkang di au sumonang do ate-ate, asa utang mandjadi singir.

Mardomu tu dalan ma hita, muda dapot eme on.

Muda di tatap ko au, sijor matamu tu halak.

Iaringot tu padantai ulang muba-uba rohamu.

Taringot tu padantai, na dung pudun matéma rohangku.
Hoe hoog gij ook stijgt, ik klim u na; waarheen gij vaart, ik volg u. Gij moet de mijne zijn!

O, waart gij de mijne, dan zou mijn hart rustiger kloppen; hoe rijk zou ik dan zijn! (eig. debet wordt credit.)

Laten we elkander op den weg ontmoeten na het snijden der padi.

Als ge mij ziet, kijk dan goed uit!

Blijf getrouw aan hetgeen wij elkander beloofd hebben.

Wat onze afspraak betreft, daarin zal ik geene verandering brengen. 


\begin{tabular}{l|l|l}
\hline INHOUD. & BETEEKENIS. & VERTALING. \\
\hline
\end{tabular}

11. Bulung ni sitarak " " sibaguri

" " sabi " " sapot

12. Bulung ni gala-gala " " bijo-bijo

3. Bulung ni gala-gala " " indot " " pau

hodong habong ni rama-rama

14. Liti Batu

15. Bulung ni kopi, Gambaran ni tomboman

16. Bulung ni haju porá " "sampilulut " " pau

17. Hodong Bulung ni timbako " " simartampuwa

18. Bulung ni indot

$$
\text { " " p pau }
$$

Intap $\mathrm{ku}$ boto na suwada, ngada husuru na mangido.

Pala gijot ko di au, rama au di ho.

Muda mate rap mate; muda mangolu rap mangolu.

Nipi muju i do nipingku, djaru paäsing-asing pepodoman.

Ulang sai pora-pora hobarmu di au, di baon dompak marsiluluton au.

Tap ko da angkang di au, tilako mandjadi tuwa.

Ingot doba au pinomat sanoli sapandjang mangolu.
Laten we nu scheiden; met Gods hulp zullen we elkander later weer ontmoeten.

Had ik geweten, dat ge niets hadt, dan zou ik u ook niets hebbenlaten vragen.

Indien gij de mijne wilt zijn, wil ik de uwe wezen.

We zullen te zamen leven of sterven.

Wat gij droomt, droom ik ook, al slapen wij ook niet bij elkander.

Spreek me niet zoo hard toe, want ik heb veel verdriet.

Als gij de mijne zijn wilt, zal miju geluk volkomen zijn.

Denk toch minstens eenmaal in uw leven aan mij. 


\begin{tabular}{|c|c|c|}
\hline I N H O UD. & BETEEKENIS. & VERTALING. \\
\hline $\begin{array}{l}\text { 19. Bulung ni haju } \\
\text { simarmonis-monis, } \\
\text { Bota }\end{array}$ & $\begin{array}{l}\mathrm{Ni} \text { parajak na sa- } \\
\text { monis, ni tadingkon } \\
\text { na sabota. }\end{array}$ & $\begin{array}{l}\text { Gij laat } u \text { door den } \\
\text { schijn verblinden. 11 }\end{array}$ \\
\hline $\begin{array}{l}\text { 20. Bulung ni unte } \\
\text { " " pau } \\
\text { sisik ni siroken }\end{array}$ & Painte au di poken. & $\begin{array}{l}\text { Wacht mij op de } \\
\text { markt! }\end{array}$ \\
\hline $\begin{array}{l}\text { 21. Bulung ni djalak- } \\
\text { djalak } \\
\text { " " pau } \\
\text { hodong } \\
\text { Bulung ni sibaguri }\end{array}$ & $\begin{array}{l}\text { Laing djalak-djalak } \\
\text { au di ho natuwari. }\end{array}$ & $\begin{array}{l}\text { Jk heb u gisteren } \\
\text { den geheelen dag ge- } \\
\text { zocht. }\end{array}$ \\
\hline $\begin{array}{ll}\text { 22. Bulung ni } & \begin{array}{c}\text { galung- } \\
\text { gung }\end{array} \\
\text { " " } & \text { pau } \\
\text { Obuk } & \\
\text { Hodong } & \end{array}$ & $\begin{array}{l}\text { Malungun magotap } \\
\text { obuk au di ho. }\end{array}$ & $\begin{array}{l}\text { Ik verlang verschrik- } \\
\text { kelijk naar } \mathrm{u} \text {. }\end{array}$ \\
\hline 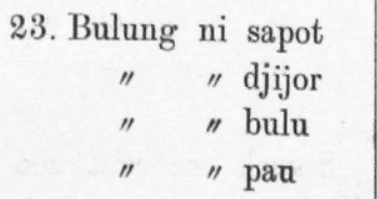 & $\begin{array}{l}\text { Intjogot rijor au } \\
\text { djolo tu djulu. }\end{array}$ & $\begin{array}{l}\text { Morgen gaik naar...; }{ }^{12} \\
\text { kom mij daar opzoeken. }\end{array}$ \\
\hline $\begin{array}{l}\text { 24. Bul. ni parira, } \\
\text { " " sumangge, } \\
\text { " " sanggar, } \\
\text { " " pau }\end{array}$ & $\begin{array}{l}\text { Maila au mambege } \\
\text { hobarmi. }\end{array}$ & $\begin{array}{l}\text { Ik schaam mij over } \\
\text { uwe woorden. }\end{array}$ \\
\hline
\end{tabular}

11 Eigenlijk luidt de vertaling: de bota laten liggen, om de monis te achtervolgen. Bota $=$ onontbolsterde rijstkorrels, die zich onder de ontbolsterde bevinden; monis $=$ gebroken rijstkorrels, rijstgruis.

$12 T u$ djulu $=$ beteekent eigenlijk: stroomop. De Bataks duiden altijd eene richting aan door vergelijking met den loop eener rivier. - Degeen, die dien brief ontvangt, begrijpt daaruit voldoende, wat de afzender bedoelt. 


\begin{tabular}{|c|c|c|}
\hline IN HOUD. & BETEEKENIS. & VERTALING. \\
\hline $\begin{array}{l}\text { 25. Bul. ni bulu tolang } \\
\text { " " silindjuwang } \\
\text { " " sanggar } \\
\text { " " pau }\end{array}$ & $\begin{array}{l}\text { Ngada tardjuwang } \\
\text { au hobar ni tulangtai. }\end{array}$ & $\begin{array}{l}\text { Ik durf mij niet te } \\
\text { verzetten tegen mijn } \\
\text { (aanstaanden) schoon- } \\
\text { vader. } 13\end{array}$ \\
\hline $\begin{array}{l}\text { 26. Bul. ni arandohot } \\
\text { " " pau } \\
\text { " " pege } \\
\text { hodong }\end{array}$ & $\begin{array}{l}\text { Dohot do au moeda } \\
\text { kehe ho. }\end{array}$ & $\begin{array}{l}\text { Als gij gaat, ga ik } \\
\text { mede. }\end{array}$ \\
\hline $\begin{array}{l}\text { 27. Bulung ni unte } \\
\begin{aligned} \text { " " pau } \\
\text { " " sapot } \\
\text { " - } \text { bargot }\end{aligned}\end{array}$ & $\begin{array}{l}\text { Painte au sintjogot } \\
\text { di toru bargot án. }\end{array}$ & $\begin{array}{l}\text { Wacht mij morgen } \\
\text { onder dien ănau-boom. }\end{array}$ \\
\hline
\end{tabular}

Een ingewikkelder briefwisseling is die, waarbij de namen der toegezonden bladeren, voorwerpen of afbeeldingen eindwoorden zijn van vierregelige versjes, ende genaamd. Zagen we zooeven b. v. wat de beteekenis is der woorden pau en simardulang-dulang, die namen zijn tevens de aanwijzers van het ondervolgende versje:

Muda mandurung ko di pau,

Tampul si mardulang-dulang;

Muda malungun ko di au

Tatap si tumondang bulan.

De beide eerste regels hebben geene beteekenis; ze dienen slechts om de rijmwoorden te plaatsen. De vertaling der laatste regels luidt:

Indien gij naar mij verlangt,

Richt uwe blikken dan naar de maan.

Nog moeilijker is het, wanneer de naam van het toegezonden voorwerp niet op het einde, maar in het midden van een regel voorkomt, b. v. tulila in de volgende ende:

1s Tulang eig. oom (moeders broeder). De gewoonte brengt mede, dat een jongen huwt met zijn nicht, dochter van den broeder zijner moeder. 
Hum tulila pe nijan,

Mangombus angin di Tabujung;

Hum huïda pe nijan,

Madung sombu halulungun.

Vertaling: Als ik u slechts zie, is mijn zielsverlangen gestild.

Dr. van der Tuuk spreekt in de "Taalkundige Aanteekeningen en Bladwijzer", behoorende bij zijne Tobasche Spraakkunst en Leesboeken, over deze ende's, die in het Tob. umpama worden genoemd. Indien men de daarin opgegevene rijmwoorden vergelijkt met die, welke in de hieronder volgende ende's gebruikt worden, zal men ontwaren, dat bij veel verschil, toch eene groote overeenkomst daartusschen bestaat. Vele der door genoemden geleerde vermelde rijmwoorden zijn namen van planten of bladeren, zoodat men mag besluiten, dat ook bij de Tobaneezen de gewoonte bestond (of bestaat), waarover wij hierboven spraken, ofschoon daarvan in de "Aanteekeningen" geene melding wordt gemaakt. Alleen wordt medegedeeld, dat dikwijls met weglating der twee laatste regels, die werkelijk iets beteekenen, zoo'n rijmpje wordt gebruikt, om iemand kennis te geven van het een of ander, dat voor derden verborgen moet blijven. Deze wijze van mededeeling zijner gedachten noemt Dr. van der Tuuk een soort van dieventaal en naar mijne bescheidene meening mag ze terecht dien naam dragen. Als men nagaat, welk een groot aantal ende's of umpama's iemand van buiten moet kennen, om op vrij zuivere wijze te kunnen zeggen, wat hem (of haar) op het hart ligt, of om een minnebrief te ontcijferen en, zooals in het door Dr. v. d. T. gestelde geval, dadelijk te weten, welke de beide laatste regels zijn van het liedje, waarvan slechts de beide eerste genoemd werden, dan zal ieder het natuurlijk vinden, dat slechts weinige, zeer weinige jongelui het ver brengen in die kunst en zal het hem begrijpelijk voorkomen, dat enkele jonge meisjes bekend zijn als vraagbaak voor minnenden. We kunnen hier met Tylor zeggen: "The examples make it evident, that they can only convey their full meaning to those, who know by heart already the compositions they refer to. They are mere Samson's riddles, only to be guessed by those who have ploughed with his heifer."

Toen eenmaal de vierregelige versjes ontstaan waren, waarin een of meer woorden in de eerste helft de gedachte door het tweede gedeelte uitgedrukt aangaven, is het natuurlijk, dat langzamerhand 
die ende's ontstonden, waarvan de beide eerste regels volstrekt geene beteekenis-aanwijzende rijmwoorden bevatten. Zij hebben met de eerste soort niets anders gemeen dan den vorm: de derde regel rijmt op den eersten, de vierde op den tweeden. Ze laten zooveel vrijheid als men slechts wenschen kan in het aantal lettergrepen van elken regel; dat de rijmen daarenboven zelve dikwijls verre van zuiver zijn, (b. v. malungun op mandurung), zal uit de volgende voorbeelden blijken. Een gevolg van deze "dichterlijke vrijheden" is, dat deze soort van ende's, om zoo te zeggen, door iederen jongeling of elk jong meisje vervaardigd kan worden; voor de vuist kunnen ze gewoonlijk bij elke gelegenheid en over elk onderwerp vier regels bij elkander brengen; zijn vier regels niet voldoende, dan worden er zes of acht samengekoppeld. Uit den aard der zaak dienen deze rijmpjes, welke wij als het derde stadium van ontwikkeling der bloementaal kunnen beschouwen, hoogst zelden als minnebrieven tusschen geliefden; meestal worden zij voorgedragen of iemand toegezongen oṕ een bizonder vervelende wijs, die al heel licht den hoorder weemoedig stemt. (Ook de ende's der eerstgenoemde soort zingen dikwijls de jongelingen en jonge meisjes elkander toe; op die wijze voldoen ze dan ook volkomen aan hunne oorspronkelijke bestemming.)

Ten slotte vermelden wij, dat gewoonlijk de jonge meisjes het verst zijn in deze soort van poëzie. Zooals bekend is slapen zij, (vooral in het Mandaïlingsche heerscht deze adat), zoodra zij huwbaar worden, niet meer bij hare ouders, maar eenigen bij elkander in de woning van eene andere ongetrouwde vrouw, (weduwe of gescheiden levende van haar' man); zoo'n slaapplaats heet podoman of partandangan. Daar kunnen zij de jongelingen ontvangen; zij staan toch steeds onder toezicht en daarenboven moet, zoolang er bezoek is, in die woning een lampje branden. 't Gebeurt wel eens dat het lichtje uitgaat: dat ligt natuurlijk aan de pit of de olie! - Merkwaardig is het, dat het bij zulk eene gelegenheid zoo lang duurt voor de lucifers voor den dag komen; gewoonlijk toch dragen de jongelui ze bij zich. Ook het flirten behoort niet tot de zeldzaamheden. Ranan iba mandjagahon horbo sabara sijan budjing sada! (of sadalak), zegt de Batak. Het is gemakkelijker op een troep (eig. een kraal) karbauwen te passen dan op één jong meisje!

In die podoman dan dragen de jonge meisjes, terwijl zij zich bezig houden met een "handwerkje", b. v. het vlechten van matjes (al of niet opengewerkt), sirihzakjes, tabaksbuidels enz., elkander 
de ende's voor, die zij van hare grootmoeders of andere onde vrouwen geleerd hebben; zoo krijgen ze eenen aardigen voorraad liedjes; haar geheugen is in dit opzicht bewonderenswaardig.

Misschien zal men denken, dat die oude vrouwtjes niet dan ongaarne de vrouwelijke jeugd die liedjes van "Lenz und Liebe, Freud' und Leid" leeren. Het tegendeel is waar! Gij moet haar hooren over den goeden, ouden tijd, als zij de jeugd onderhanden nemen. Luister maar eens!

"Aha ma songon habudjinganmuju sannari? Anggo au na djolo pandjáng budjing, ngada songon kamu-on. Au na djolo na djadijan do na huboto! Muda hum torang ari, na dung alit ma pupus di bohingku, na dung perper ma djagarku, na dung limus ma sanggulku. Anggo hamu sannari, aha mai, tuwè..... Mardoli-doli 14 pe ngada malo hamu; anggo hami na djolo, muda mangkuling sordam ni halahi di podoman, na dung kami balos mai dohot ujupujup; muda mandjodu-djodu halahi di djulu ni tapijan i, na dung kami balos mai dohot katimbung di aek-an. Songon i mada hami djolo! Ngada songon kamu-on! Edagoi! 15

"Wat zijn jelui toch voor meisjes! Dan waren wij in onzen tijd heel anders hoor! Ge hadt mij eens moeten zien; ik was van alle markten thuis! Nauwelijks stond de zon aan den hemel of ik had mịnn voorhoofd al bedekt met een geurig blanketsel ${ }^{16}$; en mijn haar was keurig opgemaakt en versierd met frissche bloemen! Maar jelui.... ba! (en terwijl ze tuwè zegt, spuwt ze minachtend op den grond). Ge weet niet eens, hoe ge u tegenover jongelui moet gedragen! Maar in onzen tijd..... Als de jongelingen in hunne slaapplaats zijnde, de sordam 17 bespeelden, dan antwoordden wij ze met de tonen van de ujup-ujup 17; en als zij, in het bad zijnde, het een of ander liedje aanhieven, dan maakten wij op onze beurt watermuziek 18. Zoo deden wij; maar jelui .... Ba!"

"En ende's, we kenden ze bij hoopen!" vervolgt zij. Op dat chapiter wilde de jeugd het oudje juist hebben; van alle kanten klinkt het: "Leer ze ons, leer ze ons!" - Trotsch op hare meerderheid tijgt ze aan het werk, met liefde en ijver, omdat zij op belangstellende, oplettende leerlingen mag rekenen.

\footnotetext{
14 Mardoli-doli zouden we kunnen vertalen door " ars amandi."

15 Edagoi = uitroep van minachting evenals turve.

10 Gewoonlijk van fijngemaakte blaren, ook hase genoemd (Ml. pupuq, kasai).

17 Blaasinstrumenten.

18 Markatimbung, tonen voortbrengen, door op eene bizondere wijze de armen of handen door het water te bewegen.
} 
Van de jonge meisjes leeren de jongelingen eenige liedjes, hetzij tijdens hunne bezoeken in de podoman, hetzij wanneer de jeugd bij lichte maan zich buitenshuis vereenigt, de meisjes om rijst te stampen of matten de vlechten, de jongelingen om gekheid te maken, al is hun scherts niet altijd fijn, of om haar het hof te maken, op alles behalve platonische manier.

Gambir ni naga sontang,

Dumarondom bona ni bulu;

Matanta pe nijan patontang

Dungma sombu halulungun.

Wanneer slechts onze blikken elkander ontmoeten, dan is mijn verlangen gestild.

2.

Ni taba siajundolok ${ }^{19}$,

Na marumbak tu haju na rumbunon;

Dung baja pabalik-balik dolok,

Ni labu tombom silungunon.

Ach, nu we zoo ver van elkander zijn, moeten we alle hoop laten varen.

Pabalik-balik dolok beteekent eigenlijk: door bergen gescheiden.

3.

$\mathrm{Ni}$ ahuwai binoto,

Dapot di sabi sarumbungan,

Ni ahuwai baja binoto,

Dapot di ari paruntungan.

Ach, wat is er an te doen? Het is besloten in 's Heeren raad!

4.

Rindang kurindangi

Sarung ni raut kubarbari,

Tu gindjang kusigei

Tu ipar ni laut kurajari.

19 Angk. hajundolok. 
Waarheen gij ook gaat, ik volg $\mathrm{u}$ overal!

Eig. : hoe hoog ge ook klimt, ik klim u na; zelfs naar den anderen oever der zee, zeil ik u na.

5.

Ambasang ni sipadjao,

Di rombar kodong do lidina;

Pamatang padaodao,

Di hombar modom do tondina.

Al zijn wij ook van elkander gescheiden, in den slaap zijn onze zielen bij elkander, (toch slapen of zijn onze zielen bij elkander).

6.

Ter! ning badja bulu,

Mangite landuk di tomboman;

Parjerbeng ni mata muju

Songon raut na tadjoman!

$\mathrm{Al}$ doet ge, alsof ge niet kijkt; uwe blikken zijn zoo scherp als messen. (Als een jongeling eenige meisjes passeert, quasi voor zich uitziende, maar in werkelijkheid haar van ter zijde bekijkende, zingen zij of een ander hem dit rijmpje toe. Van een meisje, dat zoo handelende jongelui voorbijgaat, kan het liedje natuurlijk ook gebezigd worden).

7.

$\mathrm{Ni}$ rambas unte mungkur

$\mathrm{Na}$ madabu dohot na mata,

Ngada aru binoto tutur,

Dibaon impol ni mata.

Zijne (uwe) hartstocht doet hem (u) de betrekking van bloedverwantschap vergeten.

Wordt gezegd van of tot iemand, die verliefd is op een persoon, met wie hij geen huwelijk mag sluiten.

8.

Udon do huwali,

Pardahanan tu Barumun;

Huwahuwa do ulani,

Pangantak ni na malungun.

Wat moet ik toch doen, om het weemoedig verlangen (naar de geliefde of naar huis) te doen ophouden? 
9.

Alogo ni alogo

Alogo ni tobing Barumun,

$\mathrm{Ni}$ ahuwa do ulani

Pangantak ulang malungun?

Idem als No. 8.

Harijas ni Panobasan,

Talpokon ni na mandurung;

Arijan so habolasan,

Potang ari markalalungun.

Over dag heb ik geen tijd of gelegenheid (om $u$ te zien of te spreken) en 's avonds doe ik niets dan naar u verlangen.

11.

Masa lantjat ma hinan

Masa tarutung ma sannari;

Padanta ma hinan,

Pasombu lungun ma sannari.

Denk aan onze vroegere afspraak (aan uwe belofte) en maak mij gelukkig (stil nu mijn verlangen).

12.

Manuk kulabu sende,

Na ni tambat di dulang-dulang;

Dung, baja! na so marsere,

Di langkup kalak boru tulang!

Omdat ik, helaas! zoo arm ben, is een ander met mijne geliefde gaan strijken.

13.

Si topu ma sannari

Muli sitarak do i sógot;

Martomu ma sannari

Muli marsarak do i sógot.

Laten we nu van de gelegenheid profiteeren (en bij elkander komen); we moeten later toch weer scheiden.

5e Volgr. I. 
14.

Di dok ko na so adong sorkamu,

Moldop do mata intjirmu;

Di dok ko na so adong rohamu,

Montjong do panailimu!

Ge zegt, dat ge niets van hem (haar) wilt weten, waarom volgt ge hem (haar) dan altijd met uwe oogen?

15.

Aek si mate-mate,

Paridijan ni paspas kuring;

Djaru i pe dalan mate,

Ngada tarorom so mangkuling.

$\mathrm{Al}$ zou het mij 't leven kosten, ik moet het $\mathrm{u}$ zeggen (ik moet met a spreken.)

16.

Labujir ni Tabujung,

Maluwa horbo di pompangan;

Manulak di bona bulu,

Mamún ko di bagas partandangan!

Ach , gij gaat onze kampong en uwe vrienden en verwanten verlaten!

Bona bulu: pagar van bambu om de geheele kampong; mamún vgl. mal. mămuhun.

17.

Habang tiruk barung-barung

$\mathrm{Na}$ songgop tu linggom ni bulu;

Bare, ho martaru-taru

Sanga ise pardjolo malungun!

Kom, laten we er om wedden, wie het eerst naar den ander verlangt.

Bare = mare.

18.

Tap kodong nijan di pau

Timbako ni Gunung Tuwa;

Tap ko da, angkang! di au,

Tilako mandjadi tuwa!

$\mathrm{O}$, waart gij de mijne, dan zou al mijn leed veranderen in geluk, (al mijn smart verkeeren in vreugde!)

Tap $=$ intap. 
19.

Salak do saludi

Sude palak marondo dangka;

Sadalak do na marsauli,

Sude halak marnono mata.

Slechts één valt een groot geluk te beurt en alle anderen kunnen hunne oogen niet openhouden van den slaap.

Wanneer een jongmensch in het huwelijk treedt, b. v., zorgen zijne vrienden voor alles; een der laatsten zingt dan dit rijmpje, als ze doodmoede zijn van het arrangeeren van het feest.

Marnono, Mand. = marnolnol, Angk.

Tiris sopo sijala, Idjuk ni bargot panjoloti;

Tutuma hami na sala, Aek ni bargot panopoti.

We hebben misdreven en moeten, tot onze straf, palmwijn schenken.

Wanneer een jongmensch zich aan eene geringe overtreding der adat heeft schuldig gemaakt, wordt hij door de "oudsten" der kampong beboet. In ons geval hebben een paar jongelui tot straf palmwijn te schenken; terwijl zij dien naar de sopo godang brengen, waar hij zal gedronken worden, vraagt iemand hun wat zij daar bij zich hebben. Bovenstaand rijmpje is hun antwoord.

21.

Indu dolok Sibolga,

Tontang ni parau nami;

Anggo suwada maradu lodja,

Ngada sombu roha nami.

Als wij niet met elkander wedijveren, zijn wij niet tevreden. Twee jongelingen zijn b. v. verliefd op hetzelfde meisje en trachten haar door allerlei attenties te winnen. Als iemand een hunner daarover eene aanmerking makt, antwoordt hij met bovenstaand rijmpje.

22.

Bontar batu ni salak

Lomlom batu ni saludi;

Djaru sar pe hata ni halak,

$\mathrm{Na}$ malo do budjingta marsibuni. 
Al weet ook iedereen het, zij laat er niets van blijken.

De geheele kampong weet, dat een jong meisje van iemand houdt, zij echter wil er niet voor uitkomen.

23.

Mamatangi Dja Sangkotan,

Mamatangi laho pahaè;

Muda ngada tulus kita dapotan,

Bolkasma, ale! lalu marnjaè.

Als ik hem (haar) niet krijg, wordt ik zeker ziek!

Bolkasma $=$ Mal. nistjaja.

24.

Intap kuboto paja-paja

Ngada husuwan bijo-bijo;

Intap kuboto na suwada

Ngada husuru na mangido.

Had ik geweten, dat ge niets hadt, dan zou ik $\mathrm{u}$ niets hebben laten vragen.

25.

Manjuwan Dja Sangkotan,

Marurus bulung ni ambasang;

Muda ngada tulus dapotan,

Bolkasma marnjae pasang.

Idem als no 23. Marnjae pasang = zwaar ziek zijn.

26.

Intap kodong nijan di pau

Anta marmombang do are-are;

Intap ko da angkang di au,

Anta sumonang do ate-ate.

Indien gij de mijne waart, zou mijn hart wellicht rustiger kloppen.

27.

Habang dao-dao

Na songgop marihot-ihot; (marijot-ijot)

Djaru pe padao-dao,

Laing ko do hu paingot-ingot.

Schoon ver van $\mathrm{u}$, blijf ik steeds aan $\mathrm{u}$ denken ! 
28.

Dung do sitata sitarak i.

Djolo sitanggis do so podom-podom;

Dung do hita na marsarak i,

Djolo tangis do anso modom!

$\mathrm{Na}$ ons scheiden ween ik (iederen nacht) voor ik in slaap val.

29.

Muda tulus bulu rere,

Roma hunik panggorsingi;

Muda tulus kamu kehe,

Roma hami di pudi mangihuti.

Als ge werkelijk heengaat, zullen wij (zal ik) u volgen.

30.

Dung so tola tu dolok

Pinomat tu Sajur ma tinggi:

Dung so tola dumonok,

Pinomat mata manaili.

Als ik $\mathrm{u}$ niet naderen mag, laat me $\mathrm{u}$ dan ten minste mogen zien.

31.

Andilo au andilo

Pangaraut ni tangga muju;

Mangido au mangido

$\mathrm{Na}$ ni tiktik ni tangan muju.

Ik bid, ik smeek $\mathrm{u}$, geef me een door uzelve toebereid sirihpruimpje.

$$
32 .
$$

Salimpotpot di pandan,

Salimbatuk martali puju;

Ingot ko, angkang, di padan,

Anso torkis pahae pahulu!

Vergeet, geliefde, uwe belofte niet, opdat het $u$ steeds wel ga!

33.

Tandijang gala goti,

Djumarodjak dangka ni sapot;

Marnjujang doli-doli;

Partunda budjing so dapot!

Dat jonge mensch is mager geworden, omdat hij het meisje niet heeft kunnen krijgen! 
34.

Sitata dirabi on,

So sitanggis do di bagasan porda;

Mantata di balijan,

Tai tangis do di bagasan roha.

Al ziet ge mij ook lachen, mijn harte weent.

35.

Pukpek ranggas i

Mangite landuk di Pasoman;

Panjirik ni budjing i

Songon raut na rantosan.

Zie No. 6. Panjirik is een meer gekuischte uitdrukking voor panjerbeng.

36.

Indege ni sipandurung,

Mangkabarbar mangkabaris;

Partata ni siparlungun,

Mantata na gijot tangis.

De verliefde (hij, die naar zijne geliefde verlangt) lacht, als iemand, die in tranen zal uitbarsten.

37.

Tandijang pau boti losa,

Marranting, marbulung;

Marnjijang au boti lodja,

Pangerdjeng ni na malungun.

Ik word mager en ben afgemat, ik heb rust noch duur. Mijne liefde is er de schuld van.

38

Djaru arirang ning palak,

$\mathrm{Na}$ togu do urat ni pandan sabi;

Djaru na sirang pe ning kalak,

$\mathrm{Na}$ togu do hata ni padan nami.

Al wil men ons ook scheiden, toch zullen wij onze beloften houden.

39.

Indot doba pau

Pinomat salonggi salaon;

Doeng suwada salonggi salaon, 
Pinomat salonggi saludang;

Dung suwada salonggi saludang,

Pinomat salonggi hotari;

Dung suwada salonggi hotari

Pinomat salonggi tijolu.

Ingot doba au,

Pinomat sanoli sataon;

Dung suwada sanoli sataon

Pinomat sanoli sabulan;

Dung suwada sanoli sabulan,

Pinomat sanoli sadari;

Dung suwada sanoli sadari

Pinomat sanoli sapandjang mangolu.

Denk toch aan mij minstens eenmaal per dag; als dat niet kan minstens eenmaal per maand; als dat niet mogelijk is, minstens eenmaal per jaar; als ook dat te veel is, dan ten minste eenmaal in uw leven!

Het door elkander haspelen van de vier tijdperken is een dichterlijke vrijheid of liever slordigheid, die gemakkelijk te vermijden was geweest door het omzetten van eenige regels in het eerste gedeelte; de volgorde der regels moest in beide deelen zijn 1, 6, 7, $4,5,2,3,8$.

40.

Huboto do pangirmu,

Unte na di djulu $\mathrm{i}$;

Huboto do parmanisonmu,

Talokung na di ulumi.

Ik weet wel waarom gij een bidkleed draagt; (niet omdat gij vroom zijt, maar) omdat het $\mathrm{u}$ flatteert.

Parmanison $=$ schoonheidsmiddel.

Talokung $=$ bidkleed der vrouwen, een nauw om het hoofd sluitende kaper met laag neerhangenden kraag. (Mal. tălăkung. Corr.)

41.

Intap kodong nijan di pau,

Halopa mandjadi pining;

Intap ko nijan di au

Utang mandjadi singir.

Zie: brieven, $n^{0}, 6$. 
42.

Boti bargot, boti puli,

Di djae djulu ni Barbaran;

Boti saro, boti kopi,

Boti rumput ni hadjaran!

We moeten wachtdiensten presteeren! en koffie planten! en gras suijden voor de paarden (der Europeanen!) (Wat hebben we het toch hard!)

In plaats van kopi hoort men ook kuli: goederen overbrengen.

43.

Si puntung na tartobing,

$\mathrm{Si}$ roken manopi-nopi;

Muda untung na tarlobi,

Halak tu poken, iba tu kopi!

Als we het ongelukkig treffen, moeten wij naar de koffietuinen, terwijl anderen naar de markt gaan.

44.

Intap kuligi Tano Bato,

Anta marmombang kare-kare;

Intap muli alak Ulando,

Anta sumonang kate-ate.

Als de Hollanders weg waren, zouden we 't wellicht rustiger hebben !

De drie laatste rijmpjes hoort men vooral veel in 't Mandailingsche; de koffiekultuur is daar zeer impopulair, met uitzondering der hooggelegen streken.

45.

Pala mandurung ko di pau,

Manombom ko di rungga ni bonang;

Pala malungun ko di au,

Manongos di unggas na habang!

Als ge naar mij verlangt, verzoek de vogels het mij mede te deelen!

46.

Manuk si djalang osu,

$\mathrm{Na}$ ni tambat marluwa-luwa;

Djolong-djolong marrosu,

$\mathrm{Ni}$ parduwa pining samboha. 
Met nieuwe vrienden deelt men zelfs de helft van een pinangnoot. Wordt spottenderwijze gezegd van menschen, die na korte kennismaking, " erg groot" met elkander zijn.

\section{7.}

Popoi sanggar i

Marihot bonang manalu;

Oloi hobar i,

Anso ulang hami dapotan malu.

Geef toch uwe toestemming (zeg toch ja!), opdat wij niet over de tong gaan.

\section{8.}

Harambir na masak laju,

$\mathrm{Na}$ madabu tu ogar-ogar;

Djaru tu Batak, tu Malaju,

Laing kamu do dongan sagorar!

Waar ge ook henen gaat, gij alleen zult de mijne zijn!

Dongan sagorar beteekent hier dus niet naamgenoot.

49.

Eme si laut Toba,

So eme si langge Barumun;

Djaru tu laut, tu Toba,

Laing kamu do pasombu lungun!

Waarheen ge ook gaat (waarheen ik ook ga), gij alleen kunt een einde maken aan mijn liefdesmart.

50 .

Di dok ko na so adong sorkamu,

Di tungtung ko do subang tolu;

Di dok ko na so adong rohamu,

Di poluk ko do lubang tingon toru.

Ge zegt, dat ge niets van haar weten wilt en toch tracht ge haar te spreken te krijgen (door $\mathrm{nl}$. onder het huis te gaan en op de plaats, waar het meisje slaapt, te trachten in den vloer een gat te maken of wel het een of ander tusschen de vloerlatten door naar binnen te steken.) 
51.

Sitarak dao-dao,

Mumpat-umpat batang ni sabi;

Marsarak padao-dao,

Hamu do na momo lupa di hami!

Als we ver van elkander zijn, zult gij ons (mij) wel spoedig vergeten.

52.

Hamu marbabo lupak,

Hami marbabo batangi;

Hamu do na momo lupa

Di badan si manare nami!

Wat hebt gij ons (mij) spoedig vergeten!

Simanarenami: andungvorm voor hami.

53.

Ujup-ujup parupuk,

$\mathrm{Na}$ ni solotkon di sopo saba:

Oli-oli mapukpuk,

$\mathrm{Na}$ ni opkop laing suwada.

Ik ben nitgeput en datgene, waarnaar ik zoo vurig verlang krijg ik niet.

Oli-oli mapukpuk $=$ mijne beenderen zijn kort en klein.

54.

$\mathrm{Na}$ landit ma si porkot,

Bulung dongdong gabe parada;

$\mathrm{Na}$ hantjit ma na ngotngot,

$\mathrm{Na}$ dung adong djadi suwada.

Welk een vreeselijke smart, hetgeen men het zijne heeft kunnen noemen te moeten missen!

\section{5.}

Huruntun ma rijang rijang,

Dijama marpulonggo-pulonggo;

Singgang djuguk di adijan,

Martona- tona di alogo!

Ik heb rust noch duur en draag elk zuchtje op haar te melden (hoezeer ik $\mathrm{u}$ (of haar) bemin.) 
56.

Gorgor api di bagas,

Na martinondang tu alaman;

Tibu hamu marbagas,

Anso adong doma paisorangan.

Gij moet maar spoedig trouwen, dan hebben wij een huis, waar we van tijd tot tijd kunnen komen.

57.

$\mathrm{O}$, aduma bungkulan án

Parsarangan ni borong-borong;

O, aduma bulan án,

Pardomuwan ni mata simanjolong.

Zie, de maan daar! Daar ontmoeten onze oogen elkander!

58.

Muda tulus kamu tu ranggas i,

Tadingkon sarisir di tomboman;

Muda tulus kamu na marbagas i,

Tadingkon salipi di podoman.

Als gij gaat trouwen, laat dan uw sirihzakje voor mij als een gedachtenis achter! (in uw podoman).

In uw podoman (zie hierboven.) Een meisje, dat in het huwelijk zal treden, wordt door een jongmensch verzocht een gedachtenis voor hem achter te laten bij hare vroegere slaapgenooten; een dezer vriendinnen zal zich wel met de bezorging belasten.

59.

Muda tulus ko na tu Si Galangan i,

Djumolo do sabi marpuju idjuk;

Muda tulus ko na mardalanan i,

Djumolo do hami tarkondur sibuk.

Indien gij ons (mij) verlaat, zullen wij (zal ik) spoedig wegkwijnen.

60.

Muda tulus ko na tu Si Galangan i,

Djumolo do sabi patuktuk surpu;

Muda tulus ko na mardalanan i,

Djumolo do hami manetek ilu. 
Als gij mij (ons) verlaat, dan zullen onze (mijne) tranen het eerste vloeien.

Dit en het vorig rijmpje dienen om een jongeling over te halen de kampong niet te verlaten.

61.

Ulang kamu sai mandurung,

Sanga tardurung unte tonggi;

Ulang kamu sai malungun,

Sanga tartulut dohot tondi.

Ge moet niet zoo toegeven aan uwe liefde, opdat ook uwe ziel niet krank worde.

62.

Sabi lindit sabit toto,

Salobi-lobi ni bonang rimpusu;

Dja huida, dja huboto,

Au sadjo gurgur ni pusu.

Ofschoon ik niets gezien of gehoord heb (ofschoon ik van niets weet), hebben de lui het land aan mij!

An sadjo gurgur ni pusu = milas roha ni halak mangida au!

63.

Aha be laba mandurung,

Angke madung siborang otang sasa;

Aha be laba malungun,

Angke madung siborang Muwara Sada!

Waarom zoudt ge nog naar hem verlangen, nu hij u verlaten heeft!

Muwara Sada is een riviertje bij Si Mangambat op den weg van Mandailing naar Padang Bolak (Padang Lawas) en naar Angkola. 't Is natuurlijk een Mandailingsch meisje, dat bovenstaand rijmpje haar ongelukkige vriendin toezingt.

64.

Madung djongdjong tulila,

Di dija do djait ni partimbakowan;

Madung djongdjong ahaila,

Di dija do gondjong parmanowan?

Men spreekt reeds over ons; geef mij toch uw halssnoer als gedachtenis! 
Als een meisje verloofd is geeft zij haren aanstaande een zoogenaamde "tanda"; in dit geval vraagt de jongeling haar halssnoer, een sieraad, dat door de maagden gedragen wordt. Daar de gondjong op den huwelijksdag door den echtgenoot wordt afgenomen, dringt hij dus met zijne vraag op een huwelijk aan.

65.

Inda hum porda madungdung,

Dohot do simata torus tali;

Ngada hum roha malungun,

Dohot do mata mandjalaki.

Niet alleen mijn hart verlangt naar $\mathrm{u}$, maar ook mijne oogen zoeken u overal!

66.

Mandurung na mandoran,

Isema si tompi djala;

Malungun na dung somal,

Isema pabolkas tona!

We beminnen elkander reeds zoo lang; wie zal (nu ge weggaat) u mijne woorden overbrengen?

67.

Songon dija ma pandungdung ni bulu,

Songon on dumaol-daol;

Songon dija pandokon ni lungun,

Songon on padao-dao!

Hoe $\mathrm{u}$ te zeggen, (hoezeer) ik naar $\mathrm{u}$ verlang, (hoezeer) ik $\mathrm{u}$ liefheb, als we zoo ver van elkander zijn!

68.

Muda mandurung di tuwak,

Tampar kamu pantat ni garung;

Muda malungun kamu di si manggurak,

Sanggo hamu tangan sijamun!

Als gij verlangt naar een door mij toebereide sirihpruim, (als gij aan mij denkt), kus dan uwe rechterhand.

69.

Lajang-lajang kape pidong,

Ni lompa tujung di parapi; 
Ajam-ajam ni si mangido,

Laoskon bulung rongkon api.

O, wellust van mijn oogen! geef mij een blad en wat vuur !

Een jongeling, die een meisje in haar podoman wil bezoeken, vraagt haar om een nipahblad (pusuk) en wat vuur, m. a.w. om een strootje (pangidupan). Wil zij hem ontvangen, dan geeft zij hem het gevraagde; anders zegt ze, dat ze geen vuur meer heeft.

70.

Pandjampal ni horbo Toba,

Mandjampal lao tu balijan;

Muda na suwada roha,

$\mathrm{Na}$ bahat kobar sidalijan.

Als men niet wil, kan men gemakkelijk uitvluchten vinden.

Si dalijan, vgl. Mal. dalih-dalih.

Si dalijan ook $=$ si untjok. (Verg. Bat. Wdb. i. v. bursok. Corr.)

71.

Tona ni baleo

Na gor kinan Djandji Angkola;

Di bahen suwada lehenon,

Di dokon do suwada ni roha.

Omdat ik niets ten geschenke geef, zegt ge dat ik niet van $\mathrm{u}$ houd.

72.

Uwak uwak tabolak,

Sarisir lambak ni pisang;

Ise na manintjang manggolak,

Tarida lantjat sibunijan.

Daar is iets onbehoorlijks gepleegd. Wie zal daar een stokje voor steken?

Iemand heeft gehoord of gezien, dat er iets gedaan is, strijdig met de wetten of gebruiken. Als hij daarvan mededeeling doet, weet hij zeker dat hij als getuige zal moeten optreden en eenige malen van zijn werk zal gehaald worden, of dat men het hem betaald zal zetten. Daarom zingt hij (zelfs in tegenwoordigheid der schuldigen), dit rijmpje; als iemand hem vraagt, wat hij bedoelt, antwoordt hij leukweg: $N a$ marende do au, ik zing maar wat! De achterdocht is echter opgewekt en men gaat aan het onderzoeken; de zanger heeft dan zijn doel bereikt. 
Manintjang: voor het een of ander vergrijp beboeten, b. v. met een geit of varken; ook een standje geven.

Manggolak: verbieden.

Lantjat sibunijan: eene ongeoorloofde handeling.

73.

Dung do sitata arirang i

Djolo sitanggis do so podom.

Haru landjai pordangki :

Dung do hita na sirang $\mathrm{i}$;

Djolo tangis do anso modom,

Haru sapai donganki!

$\mathrm{Na}$ ons scheiden, ween ik altijd voor ik in slaap val; (als ge mij niet gelooft), vraag het dan aan mijn vrienden.

74.

Tandak digi-digi,

Huling-kuling duwa ruwas;

Tatap ulang ligi;

Pangkulingkon ulang luwas.

Als ge naar mij (haar) kijkt, laat dan niemand het merken; als ge tegen mij (haar) spreekt, laat dan niemand het hooren.

75.

Loting ni Dja Panggilingan

Gurasana i martinggang tolu;

Matantai marsipanotnotan,

Rohai tu gindjang tu toru.

Ze kijken elkander rustig aan; maar de harten kloppen onstuimig. Dit liedje zingt iemand, wanneer hij bemerkt, dat twee personen elkander beminnen, maar 't niet durven toonen.

't Bezittelijk voornaamwoord $t a$, wordt dikwijls beleefdheidshalve of om andere redenen, in plaats van dat van den 2 en persoon gebezigd. Vgl. de uitdrukking: "Wat heb ik een plezier!" gebruikt tegen anderen, die vroolijk zijn.

76.

Magodang pe Aek Mata, $\mathrm{Na}$ marmajupan pangaritan; 
Magodang pe pamatang,

$\mathrm{Na}$ magodang di parkantjitan.

Ik ben en blijf een arme drommel, een ongelukkig mensch.

77.

Sijala urdung dolok,

Sijala urdung balijan,

Dung suwada untung sogot,

Tu Padang Bolak hamulijan.

Als de fortuin mij niet gunstig is, ga ik weg. (Eig. terug naar Padang Bolak).

\section{8.}

Djadi huarkar rere,

Tarihut do simaragong-agong;

Djaru huarkar ende,

Tarihut do sude ni na dangol!

Al zing ik ook, ik denk toch altijd aan mijn ongelukkig lot (aan mijn verdriet).

79.

Madabu ontjo di palak,

$\mathrm{Na}$ padjongdjong padang sila;

Madabu ontjo di halak,

$\mathrm{Na}$ padjongdjong ahaila.

Vloek over hen, die mij zoo'n schande hebben aangedaan! (die er de oorzaak van zijn, dat men over mij (ons) spreekt):

80.

Singkam mai djolo suwan,

Pisang siholot tabarbari;

Singkap ima djolo, tuwan!

Sanga andigan tahulai!

't Zij voor ditmaal genoeg, mijnheer! later zullen we 't nog eens hervatten. 